\title{
Ficção como crítica: notas sobre o exercício crítico-teórico no romance brasileiro recente
}

\author{
Igor Ximenes Graciano*
}

\begin{abstract}
Eu havia ido dormir como Henry fekyll e acordara como Edward Hyde. Como explicar isso?, me perguntei, e então, em novo surto de terror, indaguei também como reverter aquilo.
\end{abstract}

Robert Louis Stevenson (O estranho caso de Dr. Fekyll e Mr. Hyde)

I.

Em Conceitos de crítica, René Wellek traça um panorama do que seriam as três grandes áreas dos estudos literários. Devido em parte ao distanciamento temporal (o livro foi publicado no início da década de 1960) e ao caráter didático do texto, o que se extrai dessas definições hoje se aproxima do lugar-comum. Segundo Wellek, as grandes áreas dos estudos literários são a história da literatura, enquanto estudo das obras em "séries cronológicas", ao passo que a teoria se refere "aos princípios, categorias, modelos etc.", e a crítica à "discussão das obras concretas" (WeLLEK, 1970, p. 41).

Wellek chega a essas definições sem deixar de apontar a interdependência entre as três áreas de abordagem do fenômeno literário, afirmando que não há crítica sem teoria ou teoria sem história etc. Após essa ressalva, conclui seu argumento com uma saída pragmática e relativista. É pragmático quando afirma que "o significado de uma palavra é o que ela assume no contexto e que lhe foi imposto pelos que a empregam", e relativista por entender que "uma terminologia, particularmente em assunto tão delicado quanto a crítica literária, não pode ser congelada mesmo pela maior autoridade ou pela mais influente associação de estudiosos. Podemos ajudar a descobrir significados, a descrever contextos, a esclarecer problemas, e podemos recomendar distinções, mas não legislar para o futuro" (WELLEK, 1970, p. 41).

Doutor em Estudos de Literatura e professor de Teoria da Literatura na Universidade da Integração Internacional da Lusofonia Afro-Brasileira, São Francisco do Conde, BA, Brasil. E-mail: igor.graciano@unilab.edu.br. 
Assim, ao reiterar que o conceito das três grandes áreas dos estudos literários são o que são pelo uso que se faz deles no meio acadêmico, admitindo, contudo, que tais usos podem vir a se transformar ao longo do tempo, Wellek lava as mãos em nome justamente da manutenção desses conceitos. O recado é tácito, mas eficiente: ainda que haja controvérsias, é necessário que os profissionais do ramo conheçam o lugar e as características da teoria, da história e da crítica literária.

Aqui nos interessa sobretudo a acepção de crítica não somente como avaliação de obras concretas, mas também como disputa acerca da especificidade dos produtos literários, quando se busca discutir e legitimar se são (e porque são) literários.

II.

Estabelecidos o lugar e as subdivisões dos estudos literários, podemos pensar em outra dicotomia, a qual implica uma distinção a princípio mais radical entre obra e crítica literária. Aqui temos um contraste em que os termos da discussão muitas vezes se apresentam como antagonistas. Nesse sentido, é mais fácil entender tal polarização nas figuras de seus dois praticantes: o escritor e o crítico (aqui uso o masculino genérico com a consciência de que tais personas se fizeram a partir de um imaginário que historicamente excluiu as mulheres).

Esse imaginário, em suas cores mais fortes, costuma apresentar, de um lado, o escritor como o livre criador, dono de uma voz original, adâmica, ao passo que o crítico faz as vezes do respondente, parasitário de um discurso alheio, mas, ainda assim, legitimado a julgá-lo. Em Um crime delicado, romance em que o escritor Sérgio Sant'Anna trata dessa dicotomia de forma quase alegórica, o narrador, um crítico de teatro, afirma: "Ora, ser crítico é um exercício da razão diante de uma emotividade aliciadora, ou de uma tentativa de envolvimento estético que devemos decompor, para não dizer denunciar, na medida do possível com elegância” (SANT'ANNA, 1997, p. 18-19). Ou seja, a arte seria um discurso intuitivo, engendrado na beleza e na emotividade, enquanto a crítica representaria a frieza cartesiana da avaliação, do diagnóstico certeiro. Respectivamente, o monstro e o médico.

Se não tem início no romantismo, esse imaginário encontra sua consagração nessa escola, pois a ideia do indivíduo criador original resultou da falência do modelo crítico neoclássico, calcado em uma poética prescritiva que tinha por finalidade manter os valores de uma sociedade estamental (LimA, 1986, p. 317). Com a consolidação do modo de produção capitalista, impulsionado pela ideia de indivíduo empreendedor, parte da produção artística mais prestigiada assume um caráter contestador, ainda que sobre a mesma base: o eu original e insubstituível. Afinal, "desde que o poeta deixou de ter a sociedade estamental como horizonte, cada vez mais elegeu como centro legitimador de sua atividade a exploração de seu próprio meio de expressão: isso, paralelamente, implicava torná-lo sensível e atento à captação do recalcado e do ignorado pelo senso comum" (LimA, 1986, p. 319). 
A sociedade burguesa criou, portanto, seu pequeno monstro: a arte contraburguesa defendida, entre outros, por Baudelaire, e que atinge seu ápice nas vanguardas do início do século XX. A esses artistas não interessava agradar ao gosto do cidadão médio, antes preferindo agredi-lo, confundi-lo ou simplesmente ignorar sua sensibilidade, códigos e expectativas. Como demonstram os estudos de Bourdieu (1996) sobre o campo literário em meados do século XIX, momento de conflagração da ideologia da "arte pela arte", a popularidade e o sucesso eram tidos como vexatórios, índices de um filisteísmo ora militante ora francamente mercadológico.

Diante desse caráter doentio, monstruoso (conforme certo status quo), que a arte mais prestigiada assumiu com a ascensão do capitalismo, a sociedade burguesa precisou lançar mão de um médico capaz de sanar o corpo enfermo, visto que não seria possível se livrar dele. Esse médico é o crítico moderno, profissional munido de novas estratégias para recuperar um elemento fundamental da arte: sua capacidade de comunicar. Segundo o filósofo Gerd Bornheim, "a questão toda se concentra agora na temática da comunicação da arte [...]. É justamente a cisão entre dois tipos de estética que acaba por tornar críticos - por pô-los em crise - os níveis possíveis de comunicação entre a arte e seu público" (BorNHEIM, 2007, p. 38).

Para que os novos produtos literários pudessem entrar novamente na sala de estar burguesa, era necessário decodificá-los, justificá-los, enfim. E se a crítica moderna advém dessa cisão circunstancial nascida no romantismo e radicalizada nas vanguardas, pode-se chegar à conclusão de que sua função desde então tem sido a justificação da arte no âmbito das disputas dos campos artístico e literário. Mais que um julgamento de valor de obras específicas, a avaliação crítica busca validar tradições, as quais são oriundas de parâmetros sociais e lugares de fala concretos.

III.

Pressupondo-se que a crítica literária seja o espaço por excelência das disputas no campo literário, e considerando-se, como dito antes, que as figuras do escritor e do crítico são representadas muitas vezes como antagonistas, parece haver aí uma contradição: afinal os críticos validam certas tradições de escritores. Tal contradição é superficial, uma vez que os lugares da crítica e da criação são distintos apenas como modos de promoção de valores, estes sim compartilhados por médicos e monstros. O que está em jogo não é bem a racionalidade vampiresca do crítico versus a intuição criadora e a originalidade do escritor, e sim o que se entende por literatura e seu papel na vida social. No que se refere a esse aspecto, a crítica se coloca no entorno das obras, tidas como o verdadeiro centro da experiência estética.

O fato de um crítico humanista como George Steiner ter em seu escritório um quadro com a inscrição "Il postino" - o carteiro dos grandes autores - é significativo dessa aliança. Nesses termos, o crítico é o hermeneuta que garante a comu- 
nicação "adequada" dos textos. Devido a esse caráter regulador da experiência estética, o trabalho crítico pode limitar mais do que abrir para novas possibilidades de leitura.

O que nos interessa, no entanto, é um tipo mais complexo, porque híbrido: o escritor que também exerce a crítica. Como na alegoria de Stevenson, Dr. Jekyll e Mr. Hyde coexistem no corpo de um mesmo indivíduo, que ora é governado pela serenidade racional, analítica, do conhecimento, ora pela espontaneidade absoluta, a entrega aos apelos do corpo biológico, incongruentes com a civilidade burguesa.

No prefácio de uma coletânea de artigos críticos seus, a maioria publicada originalmente na imprensa, John Updike também recorre a uma alegoria:

A resenha literária está para a ficção e a poesia assim como velejar perto da praia está para navegar em alto-mar. Em mar aberto, temos toda aquela magnífica amplidão vazia a nossa volta, os ventos frios e radiantes, e a emoção de um vislumbre ocasional do dorso de um golfinho ou dos saltos sincronizados de peixes prateados; navegando junto à costa, sempre é possível virar de bordo e singrar ainda mais perto da terra firma com a inclusão de outra citação em corpo nove (UPDIKE, 1991, p. 11).

Ao navegar bem perto da costa, isto é, ao escrutinar e refletir sobre o texto alheio, Updike ratifica, por meio de resenhas literárias, uma visão de literatura que, afinal, coincide ou dialoga com a sua, e o faz pela exaltação ou refutação de criações de outros escritores, contemporâneos e do passado. Apontar algumas praias como hospitaleiras e denunciar outras como hostis ou inadequadas vinculase diretamente ao mergulho que Updike faz no mar aberto da própria criação. Afinal, mesmo longe da costa, há sempre a memória das praias junto às quais ele um dia singrou, seja como crítico pago por uma revista, seja como leitor de ocasião.

IV.

O que aconteceria se o monstro se apropriasse da dicção polida do médico, ou se o médico lançasse um grito gutural na sala de estar? Na novela de Stevenson, médico e monstro se expõem em habitats distintos: os ambientes privados da sociedade inglesa e as ruas desertas na madrugada de Londres. Assim, se a coexistência de dois seres, ou de dois modos de se relacionar com a literatura, é compreensível sob uma mesma assinatura autoral, desde que em momentos distintos; os termos da discussão se modificam quando o médico e o monstro se expressam ao mesmo tempo, sem que seja possível distinguir claramente quando é um, quando outro.

Não se trata mais da conhecida distinção, por exemplo, entre um Machado de Assis ficcionista frente a um Machado de Assis crítico - em que este busca, por intermédio da intervenção crítico-teórica, legitimar e inscrever aquele em determinada tradição literária -, mas de lançar tal gesto crítico no registro do literário. 
Ao se falar em crítica literária no espaço da ficção, tomando-se por objeto romances brasileiros recentes, é necessário apontar para o problema teórico dessa hipótese, e que se relaciona à especificidade do discurso ficcional. Dizer da validade ou alcance de uma proposição crítica no corpo de uma narrativa ficcional não significa que estamos a confundir autor e narrador-personagem, mas sim que tal confusão tem sido deliberadamente promovida, ainda que não assumida, pelos autores das narrativas compreendidas sob o termo genérico de autoficção. Uma vez instaurado o pacto ambíguo, nos termos de Manuel Alberca (2007), entre o registro biográfico e o romanesco, que tem sua pedra de toque na homonímia entre autor e personagem, essas narrativas causam um inegável tensionamento na recepção do romance. Afinal de contas, quem fala sob um mesmo nome? Dr. Jekyll ou Mr. Hyde?

Não é de hoje que esse tipo de confusão se dá em relação aos romances que trazem alguma coincidência biográfica entre autor e personagem, quando os leitores, profissionais ou não, se comprazem em observar um pouco da vida real no buraco da fechadura da ficção. O que há de novo, talvez, seja o lugar da literatura no mundo contemporâneo e a reiterada presença do escritor como personagem ou protagonista na prosa ficcional mais prestigiada (com prêmios importantes e trabalhos acadêmicos). Conforme a pesquisa sobre o romance brasileiro contemporâneo, coordenada por Regina Dalcastagnè (2005), escritores e escritoras têm ocupado há mais de duas décadas o topo da lista de personagens mais frequentes. ${ }^{1}$

Mais que um dado entre outros, esse pequeno exército de escritores-personagens, a maioria escrevendo sob a luz ou sombra da chamada autoficção, indica de antemão uma obsessão temática. Uma vez que o protagonista é escritor, o tema gira em torno dos bastidores, das motivações e mesmo do caráter formador da escrita literária. Sendo assim, não há nesses romances um investimento na espessura da linguagem literária, ao forjar e evidenciar sua porosidade, como se deu nas obras modernistas mais radicais, mas a exposição de aspectos ligados direta ou indiretamente à vida literária, ou às disputas que se dão no campo literário.

A voz do escritor-personagem faz ecoar, a partir desse lugar esquivo entre o biográfico e o ficcional, um conjunto de argumentos capazes de interferir no debate público das letras, seja legitimando certo conceito de literatura, seja inscrevendo e promovendo a própria obra em que são lançados com o fim de garantir sua "boa recepção". Se não é crítica no sentido ortodoxo, é crítica no sentido de uma pragmática do discurso, que tacitamente busca instaurar um viés de leitura.

No universo dos romances escritos entre 1965 e 1979, os personagens-escritores estão na terceira colocação, com 6,1\% do total. Já entre 1990 e 2004 - período em que se verifica aumento considerável do número de publicações - eles ocupam o topo da tabela, com 8,5\% do total de personagens. A pesquisadora está dando prosseguimento à catalogação dos romances a partir de 2005 . 
V.

Esses textos poderiam ser pensados como representantes do que Ludmer (2007) denominou literaturas pós-autônomas, dado o caráter limítrofe da sua escrita, situada dentro-fora das fronteiras de categorias da literatura autônoma. Contudo, na cena brasileira em que concentramos nosso foco, curiosamente o protocolo de escrita aventado por Ludmer tem sido utilizado de forma conservadora, isto é, esgarçam-se as fronteiras entre o ficcional e o biográfico para em seguida reiterar a narrativa como literatura, autônoma, ficcional. Nesse sentido, o nome próprio e os elementos documentais seriam a última fronteira para o processo de distanciamento autonômico da arte. O narrador de Antiterapias, de Jacques Fux, afirma o seguinte:

Já a verdade é a própria literatura. Ela tem compromisso com sua verdade. Qualquer que seja ela. Eu continuo não me comprometendo com ela. Primeiro, porque não conheço a minha verdade. Depois, porque a única verdade aqui é a ficção. Eu não conheço o começo da história. Muito menos seu fim. Minhas possibilidades são muitas. Ainda. As possibilidades de leitura da literatura são infindáveis. Tudo aqui é uma ficção. Autobiográfica. Testemunhal. Falaciosa (Fux, 2014, p. 178).

O narrador assim conclui após uma das muitas divagações que levam sempre à mesma constatação: tudo é ficção. Tal afirmativa surge não por acaso quando o texto se aproxima do pacto biográfico. Cultiva-se a memória, e o tipo de construção do eu que advém pelo registro das vivências do passado, para em seguida reafirmar-se a natureza literária do texto, e, mais que isso, seu caráter de obra de arte.

O trecho de Jacques Fux, professor de literatura e escritor, é exemplar da estratégia de investir na ambiguidade para depois negá-la. É possível que haja diferenças entre os conteúdos e a dicção de Fux ao argumentar como professor em comparação ao narrador de Antiterapias. A assertiva do romance é uma hipótese crítica, concebida a partir de um argumento proferido por uma voz ficcional, porém não deixa de ser uma assertiva e funciona enquanto tal. Segundo esse argumento, vida e ficção coincidem, entretanto não se confundem. Algo semelhante diz o protagonista de $O$ filho eterno, de Cristóvão Tezza, por intermédio do discurso indireto livre:

Escrevendo, pode descobrir alguma coisa, mas sem confundir - isso o escritor percebe logo - a vida e a escrita, entidades diferentes que devem manter uma relação respeitosa e não muito íntima. Sou interessante se me transformo em escrita, o que me destrói sem deixar rastro, ele imagina, sorrindo, antevendo algum crime perfeito (TezzA, 2008, p. 194). 
Se podemos concordar nesse ponto, outro parece mais controverso: há validade em proposições críticas inscritas em um romance, pela voz de um narrador ficcional? A questão está em considerar um argumento, a despeito de quem o profira.

Como lidar afinal com o narrador de Antiterapias quando este afirma que "Os versos satânicos (de Salman Rushdie) são bem banais. A crítica é fraca, simples” (p. 71)? Isso é um posicionamento do autor? Ou apenas a opinião de um personagem? De qualquer modo, entre um e outro, o julgamento sobre a obra de Rushdie está lançado, assim como a ideia de que Antiterapias, apesar das coincidências biográficas, deve ser lido como romance. Na ficção, uma chave de leitura está proposta, um típico gesto de crítica pelo qual se pretende legitimar certa posição a respeito da própria obra.

VI.

O objetivo desse aparato crítico nos romances que jogam com a ambiguidade entre o literário e o biográfico é, acreditamos, reivindicar a dimensão literária dos textos, uma vez que o literário é reconhecido como um valor. Essa ambiguidade, muito fértil quanto às possibilidades de interação com a obra, causa controvérsias no que se refere aos atributos de cada um dos gêneros textuais evocados (o romance e a biografia).

Para Lejeune, alguns romances usufruem "dos benefícios do pacto biográfico sem pagar nenhum preço por isso" (LeUjEne, 2008, p. 108). Por outro lado, Alberca (2007, p. 251) lembra que algumas autobiografias autênticas se autoatribuem o título de "romance" a fim de passar pela aduana literária e gozarem do prestígio da literatura de invenção enquanto estilização formal. De diferentes maneiras, essas narrativas jogam com a construção do eu nos limites de uma ambivalência, usufruindo às vezes do prazer voyeurístico da autobiografia, às vezes do distanciamento ficcional associado às promessas de transcendência da arte. Entre um e outro, o escritor-personagem inscreve sua presença ao mesmo tempo que consolida um julgamento.

Diante da quantidade e do prestígio dessas narrativas no campo literário brasileiro (Antiterapias venceu o prêmio São Paulo de Literatura e $O$ filho eterno o prêmio Jabuti), pode-se concluir que tal ambivalência tem exercido, paralelamente à crítica jornalística e acadêmica, um papel relevante de instalação de certo conceito de literatura, em que se advoga o que chamaríamos de perspectiva tradicional do criador. É o que Tezza chama de "sujeito-escritor" em sua biografia literária, na qual reafirma a autonomia estética e a distinção entre narrador e autor. ${ }^{2}$

Se não é novidade a inserção de argumentos críticos no espaço do romance, sua incidência hoje, pelo usufruto do entre-lugar da pragmática do discurso literário

\footnotetext{
${ }^{2}$ A esse respeito, conferir nosso artigo "O sujeito-escritor e as transformações no campo literário:
} o caso Cristovão Tezza” (Graciano, 2014). 
nesses textos, diz de uma paisagem diferenciada. Trata-se, pois, de investigar de que forma o duplo caráter dessas narrativas - objetos acabados, no sentido estático de "obra", e afirmação de uma assinatura, no sentido dinâmico de peças retóricas imbuídas de marcar ou defender um lugar no universo restrito das letras -, influenciam a recepção e buscam garantir a manutenção de valores da alta modernidade no contexto contemporâneo de consolidação do multiculturalismo.

Não pretendemos afirmar que essas características são majoritárias no cenário literário brasileiro, mas atentar para a hipótese de que o espectro autoficcional, exercido por escritores-professores, pode ser uma frente ou um modulador de crítica literária consideravelmente influente no cenário contemporâneo.

\section{VII.}

A pretensão de compreender um fenômeno a partir de qualquer essencialismo é, mais que um pressuposto teórico antiquado, algo tido por eticamente problemático desde a revisão, majoritária ao longo do século XX, de uma metafísica tida por logocêntrica e binária. O problema ético está na incapacidade dessa metafísica dar conta da complexidade, ou, em termos mais corriqueiros, da diversidade dos fenômenos e das identidades. A defesa do multiculturalismo e sua dinastia está na base de uma conduta moral que se volta para o mundo evitando-se categorias estanques, muitas vezes alheias à riqueza das experiências ou que simplesmente silenciam vozes e dicções que escapam aos lugares de fala hegemônicos.

No texto de Stevenson que tomamos como horizonte para estas notas, o uno e o binário, este último representado pela dicotomia "médico" e "monstro", razão e pulsão, é abordado com alguma desconfiança acerca de suas limitações. Ao avaliar sua experiência, Dr. Jekyll prevê a superação dessa e de qualquer dicotomia:

Dia após dia, e dos dois lados de minha inteligência, o moral e o intelectual, fui me aproximando mais e mais da verdade, cuja descoberta parcial me valeu um desastre pavoroso: a de que o homem não é de fato uno, e sim duplo. Digo duplo porque, no estágio de conhecimento em que me encontro, não posso ir além desse ponto. Outros virão, outros me superarão nessas mesmas linhas; e ouso sugerir que o homem será um dia conhecido como um conjunto de cidadãos multifacetados, incongruentes e independentes (STEVENSON, 2015, p. 125).

A unidade do sujeito moderno resta rechaçada diante "do estranho caso de Dr. Jekyll e Mr. Hyde", pois se o homem não é (e nunca foi) uno, não será tampouco duplo, mas múltiplo. A natureza humana é escorregadia, circunstancial, diaspórica.

Não se trata de contrastar alegoricamente os discursos da crítica e da ficção romanesca como elementos que guardam características intrínsecas, porém de cotejar narrativas ficcionais que instabilizam sua recepção, de maneira que o exercício 
crítico acontece no bojo de um discurso que escamoteia seu formulador, a "pessoa física”. Na ficção, a crítica lança-se como que genuína, "pura”, uma vez que é irresponsável (no sentido de "irrespondível") e mascarada na persona de um escritorpersonagem.

O jogo não acontece no âmbito formal da linguagem, como se almejou nas obras mais radicais do alto modernismo, mas no âmbito da pragmática, na interação entre o texto e o leitor. Dominique Maingueneau (1996, p. 15) afirma que "o discurso literário enquanto tal constitui uma espécie de metagênero que supõe um ritual específico e condições de êxito; um texto literário só é recebido de modo adequado se for interpretado como literário". Esse discurso se sustenta na ideia geralmente aceita de que seus conteúdos devem ser relativizados, entrevistos sempre a partir da suspensão voluntária da descrença, conforme a formulação de Coleridge. A ficção, diferentemente da crítica, é possibilidade possível, verdade como potência, não devendo se sujeitar à verificação ou concordância. Portanto, se a diferença não é imanente aos textos, será dada pelos modelos de compactuação destes com os leitores.

Quando o médico fala pelo monstro, o devir das narrativas não é serem fruídas somente enquanto obras autônomas, visto que elas são tanto o resultado estético quanto sua confabulação no campo literário. Algo como os quadros da exposição e os textos da curadoria num só corpo e momento. Corpo e gesto de Jekyll e Hyde.

\section{VIII.}

A crítica literária no corpo da ficção pode ultrapassar as pequenas disputas de campo - os discursos que buscam defender ou promover conceitos de literatura para incorporar um etos mais cívico, por assim dizer: a arte enquanto crítica social. Na cena contemporânea, tal atitude investe não somente na escrita de si como dá um passo adiante, ao afirmar que a escrita literária é uma arma contra o capital especulativo e seus artífices. É o caso do romance Divórcio, de Ricardo Lísias.

Em Divórcio, Lísias propõe sintetizar a dicotomia entre literatura do eu e literatura política. A narrativa do sofrimento íntimo do protagonista, a traição de sua esposa, justifica-se como exposição de certas práticas do jornalismo. O empenho do narrador é estabelecer uma linha reta entre seu divórcio e os desmandos de grupos sociais dominantes, representados pela grande mídia. A escrita literária, de que advém o romance, serve tanto para a superação da dor pessoal quanto para a denúncia desse jornalismo, que deve ser combativo por meio de uma textualidade que desnuda em vez de falsear. A ficção é mais portadora de verdade do que a reportagem. O narrador Lísias está "sem pele", buscando recuperar-se pela escrita:

A literatura serve-me em grande parte para isso: adoro ficar remexendo a linguagem, medindo todas as possibilidades e tentando entender até onde 
posso ir, para no final pesar o resultado e refletir para saber se o texto realmente me expressa. É a maneira que tenho, silenciosa e discreta, de sair organizadamente da confusão que tantas vezes me assalta por dentro. Se mergulhar nos ruídos do mundo exterior, nos lugares cheios de luzes, música e gente encostando em mim, vou me machucar (LísIAs, 2013, p. 37-38).

O resguardo da literatura, a fuga deliberada dos "ruídos do mundo exterior", ironicamente leva a uma exposição ainda maior devido ao voyeurismo que o relato proporciona, pois "a literatura é agora parte vital não apenas da minha vida simbólica, mas também do meu corpo" (LísıAs, 2013, p. 166). Ainda assim, o pacto romanesco não permite, ou não permitiria, a confusão entre os elementos biográficos da narrativa com a verdade dos fatos. É tudo ficção. Enquanto tal, deve "desafiar qualquer tipo de poder. Divórcio é a minha profissão de fé contra essas neoditaduras" (LísIAs, 2013, p. 184).

Até aqui o que temos é a típica justificativa para a escrita do eu em narrativas ambíguas entre os pactos biográfico e romanesco, em que se explicita certa performatividade na figura do escritor-personagem: o corpo exposto transformado em literatura. O que torna Divórcio singular na cena contemporânea é a motivação política desse gesto e a assunção de um papel social do romance incomum na chamada autoficção. Ainda que não haja uma narrativa linear, em que primeiro se explicitariam as razões da literatura do indivíduo traumatizado para, em seguida, adentrar-se no argumento político, há uma tese engendrada entre a superação do calvário vivido pelo protagonista e uma motivação que, segundo este mesmo protagonista, diz respeito à coletividade em geral, brasileira em específico.

Ricardo Lísias, o autor, acusa a insuficiência das narrativas do eu, de cunho autoficcional, para abordar os problemas da polis contemporânea. Sua saída, contudo, é arriscada, porque aposta na síntese um tanto apressada entre sofrimento individual e luta política. Mesmo que haja pontos de contato, parece não se sustentar uma relação propriamente causal entre o comportamento de sua ex-mulher e os procedimentos da grande mídia brasileira. De todo modo, a despeito de se especular aqui se esse aspecto foi literariamente bem resolvido enquanto técnica narrativa, o que ressalta é o empenho de Lísias em recuperar, no espectro autoficcional, certa função emancipatória da literatura e, claro, de seu agente, o escritor.

\section{IX.}

Abordar os discursos da crítica e da ficção romanesca, e seus entrelaçamentos, é um problema teórico da tradição literária desde pelo menos a modernidade. Como já indicamos, estabelecer um recorte com exemplos do ainda breve século XXI não facilita ou torna menos arriscada a empreitada. Ao recorrermos a algumas poucas notas, a estratégia confessada é apresentar-se mais como um conjunto de hipóteses a respeito do problema do que uma tentativa de esgotá-lo. 
A convivência, no romance, do discurso médico-crítico com a liberdade criativa do monstro-ficção não é um fenômeno novo porque efetivamente nunca pareceu razoável delimitar as fronteiras desses gêneros textuais. Como bem afirma Maria Elizabeth Chaves de Mello (1997, p. 18), "a escrita da crítica é impura, constituída pela alternância constante entre narrativização (portanto, próxima da ficção) e o exame lógico de seus dados (portanto, próximo da ciência) e vice-versa". O caráter híbrido do romance, sempre apto a abrigar outros discursos e gêneros textuais, é um dado matizado nos trabalhos de Bakhtin, ${ }^{3}$ de maneira que o alvo de nossas conjeturas não é e nem poderia ser a estrutura da prosa romanesca, mas a recepção instável causada por narradores situados entre os protocolos da crítica e da ficção.

O ensaio, outro gênero oriundo da modernidade, se carrega a duplicidade como sua marca fundamental (é expressivo ao mesmo tempo em que exercita a especulação de cunho científico), preserva, contudo, a estabilidade do autor como fundo e responsável pelos conteúdos do texto. É claro que se pode reivindicar a ficcionalidade do eu que assina os escritos ensaísticos, mas não de uma perspectiva pragmática. Quem diz nos Ensaios é Montaigne, não um narrador concebido por Montaigne e que deve ser dissociado dele. Tal diferença advém de um procedimento próprio do romance, reivindicado inclusive em processos criminais contra autores.

A tensão protocolar talvez seja a característica mais inquietante da era pósautonômica que se anuncia sob o rótulo editorial da autoficção. A narrativa ficcional padrão, com sua abertura interpretativa que apela para a resposta do crítico, ganha outro caráter diante de uma textualidade que empreende desde dentro uma pedagogia para sua recepção, como uma esfinge que sugere a resposta. No romance, a crítica não pode mais "apagar a incerteza que define a ficção", ao menos no sentido corriqueiro de discurso "em torno" das obras literárias, uma vez que ao crítico já não cabe "fazer ouvir sua voz como uma voz verdadeira” (PIgLIA, 2006, p. 13, tradução nossa).

A repercussão da crítica, que é parte significativa da vida literária, seja nos segundos cadernos, seja nas revistas universitárias, parece emigrar para o corpo do romance sem que este abra mão das regalias da autonomia estética, entre as quais está o deslocamento que a ficção possibilita diante das vicissitudes da vida. O elemento biográfico, entretanto, faz com que as narrativas mantenham uma proximidade com a vida social que é distinta do realismo literário, porque lidas também como documento. O discurso ficcional deixa aos poucos de ser uma imagem refratada do real - a realização de um imaginário - para ser pura disputa de imaginário. O "sentido" e o "valor" da obra não são negociados somente a posteriori, em uma comunidade de leitores, já que são disputados desde a obra pelo narrador-crítico.

3 Ao comparar a forma fechada da epopeia com o romance, Bakhtin (2010, p. 405) afirma que, "à diferença dos outros gêneros, o romance se formou e se desenvolveu precisamente nas condições de uma ativação aguçada do plurilinguismo exterior e interior. Este é o seu elemento natural”. 
A influência da crítica praticada no romance contemporâneo foi apenas esboçada aqui com pouquíssimos exemplos. Se não representa um fenômeno central ou majoritário do campo literário, certamente é significativo, como resultado natural da proliferação das narrativas do eu e do reiterado ruído biográfico na prosa de ficção. Ainda assim esses narradores se empenham criticamente pela manutenção do pacto romanesco e pela não confusão biográfica, a despeito do uso do nome próprio.

Se a ambiguidade é sintoma transitório do comportamento fronteiriço entre os modos autonômico e pós-autonômico ou estratégia discursiva dos autores, que oferecem biografias se passando por literatura, como já observamos com Alberca (2007), não cabe discutir agora, pois demandaria mais tempo e verbo. O que interessa, por enquanto, é apenas tornar evidente a dicção médica na voz do monstro.

$\mathbf{X}$.

A novela de Stevenson serve de farol para o tema da duplicidade e dos seres contraditórios, das identidades esquivas. Mais que uma chave de leitura, é uma imagem que ilumina sem elucidar. Tal médico-monstro, qual crítica-ficção.

Dr. Jekyll sabe que sucumbirá ao domínio de Hyde. Ele se espanta com o apego do outro à vida, o que o faz evitar, por pena de Hyde, o suicídio, única maneira de se livrar do monstro que guarda em si. Contando sua versão dos fatos em carta no desfecho da novela, Dr. Jekyll despede-se e conclui que "o que virá no futuro diz respeito a outro que não eu” (STEVENSON, 2015, p. 143). É possível que o advento da autoficção e sua duplicidade originária indique um devir em que o reconhecimento do literário esteja cada vez menos atrelado à cláusula pétrea da ficção: a separação entre autor e narrador. Ao que parece, há uma literariedade constituindose a partir de assinaturas livres da dicotomia que desabona o autor como "a voz" dos textos.

Ficcional e biográfica, imaginativa e assertiva, resta saber se a literatura será um anacronismo ou um conceito ainda relevante (e eficaz) em dias de "pós-verdade". 4

\section{Referências}

Alberca, Manuel. El pacto ambiguo. De la novela biográfica a la autoficción. Madrid: Biblioteca Nueva, 2007.

4 O termo "pós-verdade" tem sido empregado com frequência no debate contemporâneo, especialmente no âmbito das redes sociais, e se refere a uma convicção que independe da averiguação das fontes ou mesmo da confirmação ou refutação dos fatos. 
BAKHTIN, Mikhail. Epos e romance (sobre a metodologia do estudo do romance) In: BAKнtin, Mikhail. Questões de literatura e de estética: a teoria do romance. 6. ed. São Paulo: Hucitec, 2010.

Bornhein, Gerd. As dimensões da crítica. In: Martins, Maria Helena (Org.). Rumos da crítica. 2. ed. São Paulo: Senac; Itaú Cultural, 2007.

Bourdieu, Pierre. As regras da arte: gênese e estrutura do campo literário. Tradução de Maria Lúcia Machado. São Paulo: Companhia das Letras, 1996.

DALCASTAGnè, Regina. A personagem no romance brasileiro contemporâneo. Estudos de Literatura Brasileira Contemporânea, Brasília, n. 26, p. 13-71, 2005.

Fux, Jacques. Antiterapias. Belo Horizonte: Scriptum, 2014.

Graciano, Igor Ximenes. O sujeito-escritor e as transformações no campo literário: o caso Cristovão Tezza. Estudos de Literatura Brasileira Contemporânea, Brasília, n. 43, p. 277-291, 2014. Disponível em: http://periodicos.unb.br/index.php/ estudos/article/view/10774

Lejeune. Philipe. O pacto autobiográfico. Organização de Jovita Maria Gerheim Noronha; Tradução de Jovita Maria Gerhein, Maria Inês Coimbra. Belo Horizonte: Editora da UFMG, 2008.

LimA, Luiz. Sociedade e discurso ficcional. Rio de Janeiro: Guanabara, 1986.

LísIAs, Ricardo. Divórcio. Rio de Janeiro: Objetiva, 2013.

LudMer, Josefina. Literaturas postautónomas. Ciberletras, New York, n. 17, 2007. On-line. Disponível em: http://www.lehman.cuny.edu/ciberletras/v17.html

Maingueneau, Dominique. Pragmática para o discurso literário. São Paulo: Contexto, 1996.

Mello, Maria Elizabeth Chaves de. Lições de crítica: conceitos europeus, crítica literária e literatura crítica no Brasil do século XIX. Niterói: Eduff, 1997.

Piglia, Ricardo. La lectura da la ficción. In: Piglia, Ricardo. Crítica e ficción. Barcelona: Anagrama, 2006.

Sant'anna, Sérgio. Um crime delicado. Companhia das Letras: São Paulo, 1997.

Stevenson, Robert Louis. O médico e o monstro: o estranho caso de dr. Jekill e sr. Hyde. Tradução de Jorio Dauster. Prefácio de Luiz Alfredo Garcia-Roza; introdução e notas de Robert Mighall. São Paulo: Penguin Classics; Companhia das Letras, 2015.

TezzA, Cristovão. O filho eterno. 6. ed. Rio de Janeiro: Record, 2008.

Updike, John. Prefácio In: Updike, John. Bem perto da costa. Tradução de Carlos Afonso Malferrari. São Paulo: Companhia das Letras, 1991. 
Wellek, René. Termo e conceito de crítica literária. In: Wellek, René. Conceitos de crítica. Tradução de Oscar Mendes. São Paulo: Cultrix, 1970. p. 29-41.

Recebido em 15 de agosto de 2018.

Aprovado em 26 de setembro de 2018.

\section{Resumo/Abstract/Resumen}

Ficção como crítica: notas sobre o exercício crítico-teórico no romance brasileiro recente

\section{Igor Ximenes Graciano}

Pretendemos, neste artigo, fazer alguns apontamentos a respeito do exercício da crítica em romances brasileiros recentes com o fim de investigar como se dá o trabalho crítico em um âmbito que, a princípio, não lhe é propício, dado o distanciamento normalmente desejado entre narrador ficcional e autor empírico. Trata-se, portanto, de investigar o duplo caráter dessas narrativas, que são objetos acabados, no sentido estático (e estético) de "obra", e afirmação de uma assinatura, no sentido dinâmico (e crítico) de peças retóricas imbuídas de marcar ou defender um lugar no atual campo literário brasileiro.

Palavras-chave: ficção, crítica, romance contemporâneo.

Fiction as criticism: notes on the critical-theoretical exercise in the recent Brazilian novel

\section{Igor Ximenes Graciano}

We intend, in this article, to make some notes about the exercise of criticism in recent Brazilian novels in order to investigate how critical work takes place in a scope that, at first, is not conducive to it, given the normally desired distancing between fictional narrator and empirical author. It is therefore a matter of investigating the dual character of these narratives, which are finished objects in the static (and aesthetic) sense of "work", and affirmation of a signature in the dynamic (and critical) sense of rhetorical pieces imbued to mark or defend a place in the current Brazilian literary field.

Keywords: fiction, criticism, contemporary novel. 
La ficción como crítica: notas sobre el ejercicio teórico-crítico en la novela reciente brasileña

\section{Igor Ximenes Graciano}

En este artículo nos proponemos hacer algunas notas sobre el ejercicio crítico en la novela brasileña reciente, con la finalidad de investigar la forma en la cual normalmente se requiere trabajo crítico, en un ambiente que, por principio, no le es propicio, dada la distancia entre el narrador ficticio y el autor empírico. Se trata, por lo tanto, de investigar el carácter dual de estos relatos, que son objetos terminados en el sentido estático (y estético) de "trabajo", y la afirmación de una firma en el sentido dinámico (y crítico) de piezas retóricas imbuidas de una marca o defensa de un lugar en el campo literario brasileño actual.

Palabras clave: ficción, crítica, novela contemporánea. 